\title{
Çocukların ve Ebeveynlerinin Oral Hijyen Alışkanlık (OHA) Düzeylerinin Karşılaştırılması ve Değerlendirilmesi
}

\section{Comparison And Evaluation Of The Oral Hygiene Habits Of Children And Their Parents}

\section{Esra KARAAĞAÇ * \\ Çiğdem \\ KÜÇÜKEŞMEN **. \\ *: Uzm. Dt., Süleyman \\ Demirel Üniversitesi, Diş \\ Hekimliği Fakültesi, \\ Pedodonti ABD, Isparta, \\ Türkiye. \\ **:Prof. Dr., Süleyman \\ Demirel Üniversitesi, Diş \\ Hekimliği Fakültesi, \\ Pedodonti ABD, Isparta, \\ Türkiye.}

Yazışma Adresi:

Uzm. Dt. Esra Karaağaç

SDÜ Diş Hekimliği

Fakültesi, Pedodonti ABD,

Doğu Kampüsü, Çünür,

Merkez/Isparta Tel: 0246

2113349

e-mail:

dtkaraagac@hotmail.com
Öz

Amaç; Çalışmamızda, hastaların ve ebeveynlerinin ağız ve diş sağ lığı için kullandıkları oral hijyen araçlarının kullanım sıklıklarını tespit etmek, çocukların oral hijyen alışkanlıkları (OHA) kazanmasında ebeveynlerin ne kadar etkili olduğunu değerlendirmek ve ebeveynleri oral hijyenin önemi hakkında yeterli düzeyde bilgilendirmek amaçlanmaktadır. Gereç ve Yöntem; Araştırmada, Pedodonti ABD Kliniği'ne başvuran 12-14 yaşları arasındaki 360 çocuk hastanın DMFTİndeksinegöreçürükinsidansı, organoleptikyöntemegöreağız kokusu olup olmadığı, dişlerini firçalarken kanama durumu değerlendirilmiştir. Başvuran hastaların ve ebeveynlerinin (352 anne, 332 baba) oral hijyen alışkanlıkları (diş fırçalama sıklıkları, diş ipi ve ağız gargarası kullanımı, dil temizliği) da değerlendirilip birbirleriyle karşılaştırılmıştır. Bulgular; Çocuklarda DMFT İndeksinin, yaşla birlikte artış gösterdiği belirlenmiştir. Bununla birlikte, çalışmaya katılan çocukların neredeyse yarısında hekim tarafından $(\% 42,7)$ ağız kokusu olduğu tespit edilirken, başvuranların \% 33'ü ağız kokusu şikayeti olduğunu belirtmişlerdir. Çocukların \% 5'i dişlerini hiç fırçalamadıklarını belirtirken, bu değer ebeveynlerde \% 13,7 olarak belirlenmiştir. Sonuç; Diş ipi ve ağız gargarası kullanımı, dil temizliği, diş̧ fırçalama gibi oral hijyen alışkanlıklarının, çocuklar ve ebeveynleri arasında düzenli olarak uygulanmadığ 1 tespit edilmiştir. Ebeveynlerin OHA'larının yetersiz olmasının ve bu konuda çocukları bilgilendirmemelerinin, çocukların da OHA'larına yeteri kadar özen göstermemelerine neden olduğu sonucuna varılmıştır.

Anahtar Kelimeler: Oral hijyen alışkanlıkları, DMFT, ağız kokusu, oral hijyen

\footnotetext{
Abstract

Objective: In this study, our aim is to determine the usage frequency of oral hygiene devices, used by patients and their parents
} 
for oral and dental hygiene, to assess the effectiveness of parents in obtaining children's oral hygiene habits, and to inform parents enough about the importance of oral hygiene. Material and Methods: In the study, 360 children between the ages of 12-14 who applied to the Department of Pedodontics were evaluated for caries incidence according to the DMFT Index, oral malodor according to the organoleptic method,bleeding status during brushing. Oral hygiene habits (toothbrushingfrequency,

flossingandmouthwashing, tongue cleaning) of the patients and their parents (352 mothers, 332 fathers) were also evaluated and compared with each other. Results: The DMFT index in children was found to increase with age. However, almost half of the children who participated in the study were found to have oral malodor by the physician $(\% 42.7)$ and $\%$ 33 of the children complained of oral odor. While $\% 5$ of the children stated that they could not brush their teeth at all, this value was determined as $\% 13,7$ in the parents. Conclusion: It has been determined that oral hygiene habits such as flossing and mouthwashing, tongue cleaning, toothbrushing are not routinely applied between children and their parents. It was concluded that parents' inadequacy of OHA and their informing of children in this regard caused children not to pay enough attention to their OHA

Keywords: Oral hygiene habits, DMFT, oral malodor, oral hygiene

\section{Giriş}

A ğız ve diş sağlı̆̆ı, genel sağlığımızın önemli bir kısmını oluşturmaktadır. Çocukların daha iyi ağız ve diş sağlı̆̆ına sahip olmaları ve oral hijyen alışkanlıkları kazanmalarında, ailelerin oral hijyene verdikleri önem ve ailesel tutumlar büyük bir rol oynamaktadır. Aile, sağlıklı bir yaşam için çocuklara gerekli ortamı yaratarak çocuğun kendine güvenini arttırır ve oral hijyen alışkanlıklarının oluşmasına yardımcı olur (1). Çocuk ve adölesanlarda zayıf ağız ve diş sağlığ1; konuşmanın gelişimi üzerinde olumsuz bir etkiye neden olmakla birlikte, sosyal olarak kabullenmeyi de etkileyip bireylerin toplum içinde küçük düşmelerine sebep olabilmektedir. Ayrıca yüksek çürük insidansları yemek yeme sırasinda fonksiyonel, gülümseme gibi fonksiyonlar sirasinda ise estetik sorunlar meydana getirmekle birlikte çocuklarda yaşam kalitesinin bozulmasina da neden olmaktadır (2).

Günümüzde daha iyi ağız ve diş sağlığ kazanıl - masında, oral hijyen alışkanlıklarının gerekliliği ve önemi çoğu birey tarafından bilinmesine karşın, alışkanlıkların uygulanmalarında yetersizlikler olduğu görülmektedir. $\mathrm{Bu}$ bakımdan hem hastaların hem de

ebeveynlerin bilgilendirilmesi ve motive edilmesiyle birlikte, bireylerin ağız hijyenini etkin bir biçimde sağlaması da hedeflenmektedir. Sağlıklı ağız ve diş sağlığı, bireylerin ağız hijyen alışkanlıklarını doğru ve düzenli olarak uygulamalarına bağlıdır (3).

Çalışmamızda, Pedodonti Kliniği'ne başvuran 12-

14 yaşları arasındaki hastaların ve ebeveynlerinin ağı ve diş sağlığ için kullandıkları oral hijyen araçlarının kullanım ve uygulama siklıklarının tespit edilmesi, çocuklara oral hijyen alışkanlıklarının kazandırılmasında ebeveynlerin ne düzeyde etkili olduklarının öneminin vurgulanması ve ebeveynlerin bu konu hakkında yeterli düzeyde bilgilendirilmeleri amaçlanmıştır.

\section{Gereç ve Yöntem}

Bu çalışmada, Süleyman Demirel Üniversitesi Diş Hekimliği Fakültesi Pedodonti Anabilim Dalı Kliniği'ne başvuran 12-14 yaşları arasındaki 360 hasta (203 kı, 157 erkek) ağız ve diş sağlığı ve oral hijyen alışkanlıkları 
bakımından değerlendirilmiştir.

Çocuklardaki diş çürüğü görülme sıklığı için 1938 'de Klein, Palmer ve Knutson tarafindan geliştirilmiş DMF sistemi kullanılmıştır. $\mathrm{Bu}$ sistemde, D (decay) çürük, M (missing) kayıp, F (filled) dolguyu ifade etmektedir (4). Hekim tarafindan, 360 hastanın (157 erkek, 203 kı), organoleptik yöntem aracılığıyla ağız kokusu varlığ 1 incelenmiş ve kendi algılamalarına göre ağız kokusu şikayeti olup olmadığı değerlendirilmiştir. Organoleptik ölçüm, hastanın ekspire ettiği havanın hekim tarafindan koklanması esasına dayanır. Buna göre değerler; 0-5 arasında elde edilen skorlarla değerlendirilir. Çalışmamızda, hastalarda ağız kokusu olup olmadığı incelenirken 0 skor (koku yok) dışındaki skorlara sahip olan hastalar, "ağız kokusu mevcut" olarak değerlendirilmiştir.

Çocuklara, dişlerini fırçalama sırasında dişetlerinde kanama olup olmadığı sorulmuş olup, hem çocukların hem de ebeveynlerinin oral hijyen alıșkanlıklarını (diș firçalama sıklıkları, diș ipi ve ağız gargarası kullanımı, dil temizliği) ne kadar sıklıkla yaptıklarını belirtmeleri istenmiş ve bulunan değerler yüzdesel hesaplanarak sonuçlar elde edilmiştir.

\section{Bulgular}

Çalışma grubunun, DMFT İndeks değeri 4,12 olarak tespit edilirken, bu oran kızlarda 4,19; erkeklerde ise 4,04 olarak bulunmuştur. Yaş gruplarına göre bakıldığında; DMFT değeri, 12 yaşındakilerde 3,34 ;

13 yaşındakilerde 4,$24 ; 14$ yaşındakilerde ise 4,76 olarak hesaplanmıştır (Tablo 1).
Tablo 1:Yaş gruplarına göre DMFT değerleri

\begin{tabular}{|c|c|}
\hline Yaş Grupları & DMFT değeri \\
\hline 12 & 3,34 \\
\hline 13 & 4,24 \\
\hline 14 & 4,76 \\
\hline
\end{tabular}

Hastaların yaşlarının artmasıyla birlikte, çürük insidanslarının da arttığı görülmüştür. Fırçalama sıklığına göre, hastaların $\% 5$ 'i dişlerini hiç fırçalamadıklarını; $\% 44,1^{\prime} i$ ara sıra; $\% 35,5^{\prime} \mathrm{i}$ günde $1 \mathrm{defa}, \% 15^{\prime} \mathrm{i}$ günde 2 defa, \%0,2‘si günde 3 defa dişlerini firçaladıklarını ifade etmişlerdir. Dişlerini firçalama esnasında diş etlerinde kanama olduğunu belirten hastalar, çalışma grubunun \% 59'unu oluşturmuşlardır. Ağız kokusu şikayeti olanlar, çalışmaya katılanların \%33' üdür. Hekim tarafindan organoleptik yöntemle ağız kokusu incelendiğinde, ağız kokusu olmayan hastalar \%42,7 oranında tespit edilmiştir. Diş ipi kullanan hastalar, çalışma grubunun \% 3,6'sını; dil temizliği yapanlar \% 24' ünü, ağız gargarası kullananlar ise hastaların \%1,9'unu (Tablo 2) oluşturmaktadır. Çalışmaya katılan 684 ebeveynin (352 anne, 332 baba); \%13,7'si dişlerini hiç fırçalamadıklarını ifade ederken (\%75 baba, $\%$

25 anne), ara sıra firçalayanlar ise ebeveynlerin

\%37,8' ini olușturmaktadır. Ebeveynlerin oral hijyen alıșkanlıkları; diș ipi kullananlar \%4,6, dil temizliği yapanlar \% 7,7, ağız gargaras1 kullananlar ise \%2,9 olarak belirlenmiştir (Tablo 2).

\section{Tartışma}

Birçok alışkanlığın çocukluk döneminde 
kazanılması, çocuğun büyüme ve gelişiminin devam ettiği bu dönemde ağı sağlı̆̆ının önemli olması, çocuk hastalarda ağız ve diş sağlığı düzeylerinin araştırılmasını, tedavi ihtiyaçlarının belirlenmesini ve sağlıklı ağız ve diş sağlığına ulaşılması için hasta ve ebeveynlerin yeterli düzeyde eğitilmelerini önemli kılmaktadır. Astrom ve Jakobsen (5), ağız ve diş sağlığı ile ilgili davranışlarda, ebeveynlerin davranışlarını, çocukların taklit ettiklerini belirterek, diş firçalama, diș ipi ve ağız gargarası kullanımı, dil temizliği gibi oral hijyen alışkanlıklarında ailenin model olmasının çocuklar için önemli olduğunu, ayrıca ebeveynlerin diş sağlığına yönelik davranışlarının ergenlik çağına kadar çocuğun davranışlarında doğrudan doğruya etkili olduğunu da bildirmektedirler.
Diş çürüklerinin prevalansları yapılan çalışmalarda değerlendirildiğinde; 13-17 yaşları arasındaki 568

çocukta, \%78,2, 15-16 yaşlarındaki çocuklarda

$\% 75,5$ olarak gözlemlenmiştir (6). Nibras ve ark.

(7) çürük prevalansını 12 yaşındaki çocuklar arasinda \%62, Al-Sharabati ve ark.(8) ise \% 61,9 olarak değerlendirmişlerdir. Meksika' daki 12-

15 yaşları arasındaki çocuklar arasında ise daha düşük çürük prevalansı $(\% 48,6)$ gözlemlenmiştir (9). Çalışmamızdaki ortalama DMFT değeri; 3,7 olarak bulunurken bu sonuc Suudi Arabistan' daki $13-15$ ve 16-18 yașları arasındaki çocuklarda bulunan DMFT oranlarına benzerlik göstermektedir (10).

Tablo 2:Hastalar ve ailelerinin oral hijyen alışkanlıklar1

\begin{tabular}{|c|c|c|c|c|c|}
\hline \multirow{2}{*}{} & \multicolumn{2}{|c|}{ Diş fırçalama sıklıkları } & \multicolumn{2}{|c|}{} \\
\cline { 2 - 6 } & Hiç & Ara sıra & $\begin{array}{c}\text { Diş ipi } \\
\text { kullanımı }\end{array}$ & Dil temizliği & $\begin{array}{c}\text { Ağız gar- } \\
\text { garası }\end{array}$ \\
\hline Hastalar & $\% 5$ & $\% 44,1$ & $\% 3,6$ & $\% 3,6$ & $\% 1,9$ \\
\hline Aileler & $\% 13,7$ & $\% 37,8$ & $\% 4,6$ & $\% 7,7$ & $\% 2,9$ \\
\hline
\end{tabular}

Al-Darwish ve ark. (11) yaşın artmasıyla bera- rilmiş, bu sonuca göre DMFT değerinin yaşla ber DMFT değerlerinde de artış (12 yaş birlikte artış göstermiş olduğu ve çalışmamızın DMFT 4,62, sonuçlarıyla benzerlik gösterdiği gözlemlenmiş-

13 yaş DMFT 4,79, 14 yaş DMFT 5,5) olduğunu tir.

belirtmektedirler. Shailee ve ark (12), 12 ve 15 Kızlarda dişlerin erüpsiyon zamanının, erkekleryaşlarındaki çocukların DMFT İndekslerini in- den yaklaşık 10 ay daha önce başlaması, puberte celeyip birbirleriyle karşılastırmışlar. DMFT çağında hormonal değişiklikler nedeniyle periodeğerleri, 12 yaşındakilerde $0,62 \pm 1,242$ iken dontal sorunlar ortaya çıkması, kızların dişleri15 yaşındakilerde $1,06 \pm 2,93$ olarak değerlendi- nin çürük risk faktörlerine daha erken maruz 
kalmasında rol oynayan faktörler arasındadır (13). Nitekim bizim çalışmamızda da, DMFT değeri kızlarda $(4,19)$, erkeklere $(4,04)$ göre daha fazla olarak belirlenmiştir. Sağlıklı bir ağız-diş sağlığının kazanılmasında en önemli görev kişinin kendisine düşmektedir. Dişlerin sağlıklı bir durumda varlığını korumasını sağlamak için, günlük ağız bakım işlemleri ile (diş firçalama, diş ipi kullanma gibi) bakteriyel diş plağının uzaklaştırılması gerekmektedir. Dişlerini düzenli firçalamayan çocuklarda bakteri plağ 1 dişlere yapışır ve temizlenmediği sürece bu durum diş çürüklerinin ve hatta diş taşlarının meydana gelmesine kadar ilerleyerek çocuğun genel sağlığını da etkileyebilmektedir (14).

Çocukların diş firçalama sıklıkları yapılan çalış - malarda çeşitli farklılıklar göstermektedir. 2000 yılında Riyad da yapılan bir çalışmada; 5-12 yaşları arasındaki çocukların \% 10,7' sinin dişlerini fırçalamadıkları, \%58,8'inin ara sıra, $\%$ 23,5' inin günde bir kez ve $\% 7$ 'sinin günde iki kez olacak sıklıkta dişlerini firçaladıkları görülmüştür (15). Motlagh ve Kohestani (16), yaptıkları çalışmada ise 12 yaşlarındaki öğrencilerin \% 88,8' inin dişlerini günde bir veya birden daha fazla firçaladıklarını, \% 11,1 'inin ise dişlerini hiç firçalamadıklarını belirtmişlerdir. Çalışmamızda ise, hastaların \%5'i dişlerini hiç fırçalamadıklarını belirtirken, sadece $\% 0,2$ ' si günde 3 defa dişlerini firçaladıklarını ifade etmişlerdir. Shailee ve ark. (12), yaptıkları çalışmalarında 12 yaşındaki

hastaların büyük çoğunluğunun (\%64) dişlerini günde sadece bir kez firçaladıklarını gözlemlerken, bizim çalışmamızın büyük çoğunluğunu dişlerini ara sıra firçalayanlar $(\% 44,1)$ oluştur- muştur. Ebeveynlerin \% 37,8' i dişlerini ara sıra fırçaladıklarını belirtmişlerdir. Çalışmamızdaki çocuk ve ebeveynlerinin diş firçalama sıklıklarının düşük olmasının nedenleri arasında, ağız ve diş sağlığı hakkında bilinç seviyelerinin azlığı, düşük sosyo-ekonomik durum ve eğitim seviyeleri, ailelerin çocuklarının diş sağlığına verdikleri değerin yetersizliği gösterilebilir.

Mehtave Kaur(17), Hindistan'dayaşayan 12 yaşındaki 440 çocuğun 1 yıllık takibinde \% 41,8' inin günde en az bir kez, \% 25' inin dişlerini günde birden daha fazla (bu oran Zhu L ve ark.larının (18) yaptıkları çalışmayla kıyaslandığında daha az), \%32’ sinin ise günlük olarak dişlerini fırçalamadıklarını gözlemlemişlerdir. Mehta ve Kaur (17), çalışmalarındaki hastaların büyük çoğunluğunun $(\% 83,2)$ düzenli diş firçalamanın çürükleri önlemedeki öneminin farkında olduğunu belirtmişlerdir. Bu oran, Varenne ve ark.larının (19) çalışmalarının bulgusuna benzerlik göstermektedir. Irak'ta yapılan bir çalışmada ise, diş firçalama alışkanlığı ile yaşları 13-17 arasında olan çocukların diş çürüğü prevalansı ve şiddeti arasındaki ilişkili istatistiksel olarak anlamlı düzeyde bulunmamıştır $(\mathrm{p}<0,05)(13)$.

Cinsiyetlere göre değerlendirme yapıldı̆̆ında, kızların erkeklere göre, ağız ve diş sağlığı uygulamalarına daha fazla değer verdikleri de görülmüştür $(17,20)$. Buna neden olarak, kızların kendi kişisel ve dişsel görünümlerine erkeklere göre daha fazla önem verdikleri için, oral hijyen alışkanlıklarının düzenli yapılmasının bilincinde olmaları gösterilebilir.

Diş ipi kullanımı; ara yüz plak kontrolü ve diş eti hastalıklarının önlenmesinde en çok kullanılan oral hijyen araçlarından biridir. Diş fırçası 
ara yüz bölgesine erişemediği için, diş ipi kullanımı ile birlikte dişlerin ara yüzünden plak ve diş taşı uzaklaştırılır böylelikle ara yüzdeki dişetinin enfeksiyona karşı direnci artar (21).

Yapılan bir çalışmada; yüksek eğitim seviyesine sahip ailelerin çocuklarının düşük eğitimli ailelerin çocuklarına göre günde 2 defa dişlerini firçaladıkları görülmüş olup çocukların \% 21,8' inin diş ipi kullandığı ve bu çocukların genellikle yüksek eğitim seviyesine sahip ailelerin çocukları oldukları anlaşılmıştır (22). Çalışmamızda, çocuklar ve ebeveynleri arasında diş ipi kullanımının çok düşük düzeylerde (sırasıyla \% 3,6 ve \% 4,6) olmasinın nedenleri arasında; ailelerin düşük eğitim ve sosyo-ekonomik seviyesi, ağız ve diş sağlığına verdikleri önemin az olması gösterilebilir.

Dilin temizlenmesi, dil pasını, bakteri besinlerini, mikroorganizma sayısını ve ağız kokusunu azaltmaktadır. Uçucu sülfür bileşikleri, diş firçasının kullanımıyla \% 33, özel olarak tasarlanmış bir dil temizleyicisi ile ise \%42'ye kadar azalmaktadır (23). Ağız kokusuna neden olan uçucu sülfür içeren bileşen seviyesinin, dişleri ve dili firçalayıp ve ağzı suyla çalkalayarak en az bir saatte azaldığ da gösterilmiştir (24). Çalışmamızda, hastaların \% 24' ünün dil temizliği yaptığı değerlendirilirken, bu değer ebeveynlerin arasında \%7,7 olarak tespit edilmiştir. Oral hijyen alışkanlıklarından olan dil temizliğine karşı ebeveynlerin ilgisiz kalmalarının, çocukların tutumlarını da etkilediği ortaya çıkmaktadir.

Çocuklarda diş firçalarken diş eti kanaması olması, zayıf ağız ve diş sağlığına, yetersiz ağız bakım alışkanlıklarına, karışık dişlenme periyoduna, süt dişlerinin düşmesine ve kızlar- daki pubertal değişikliklere bağlı olabilmektedir. Bodur ve ark.

(25) $11-12$ ve 14-15 yaş gruplarında yaptıkları bir çalışmada diş eti kanaması oranını sırasıyla \% 54 ve \% 36 olarak tespit etmişlerdir. Çalışmamızda ise, dișlerini firçalarken diş eti kanaması olduğunu belirten hastalar çalışma grubunun yarısından fazlasını (\% 59' unu) oluşturmaktadır.

Halitozis toplumun birçok kesimini etkilemektedir. Çocuklar için ağız kokusunun ülkemizde en çok gözlemlendiği dönem, ergenlik dönemi olarak bildirilmiș olup objektif değerlendirilmesi zor olduğu için gerçek prevalansı da kesin olarak bilinmemektedir (26). 7-11 yaşları arasındaki 628 çocuk üzerinde yapılan bir araştırmada, ağız kokusu görülme sıklığı

\% 14.5 olarak kaydedilmiş ve yaş artışı ile ağız kokusu arasında anlamlı bir korelasyon gözlemlenmiștir. Bunun yanı sıra; diș firçalama sıklığının ağız

kokusunu etkilemediği de rapor edilmiştir (27). Yaşları 15-17 arasında olan 474 çocuk üzerinde yapılan başka bir çalıșmada ise, çocukların \% 39'unda ağız kokusu tespit edilmiştir (28). Çocuklarda halitozis prevalansının $\% 5$ ile 75 arasında olduğu belirtilmiştir (29). Çalışmamızda ise, diş hekimi tarafından değerlendirme sonucunda ağ1z kokusu olan hastalar çalıșma grubunun $\% 57,3$ 'ünü oluștururken, hastaların \% 33'ü ağ1z kokusu şikayetinin olduğunu belirtmişlerdir. Hastalarda ağız kokusu olup olmadığı değerlendirilirken; çalıșmamızda da kullandığ1mız ağı kokusu ölçüm yöntemlerinden organoleptik yöntem kolay ve ekonomik olmasından dolayı tercih edilse de, ölçüm yapan kişilerin yaptıkları ölçümlerin güvenilirliğinin geliştirilmesi gerekmektedir. 


\section{Sonuç}

Çocukların oral hijyen alışkanları, ebeveynlerin yetersiz düzeylerdeki oral hijyen alışkanlıklarından olumsuz biçimde etkilenmektedir. Çocukların ve ailelerinin oral hijyen alışkanlıklarının geliştirilmesi için, daha fazla bilgilendirilmelerinin gerekli olduğu düşünülmektedir. Ebeveynlerin çocuklarının diş sağlığı ile ilgili doğru yaklaşımları uygulayabilmeleri için; iyi bir ağız hijyeninin sağlanması hakkında gerekli bilgileri belli bir düzeyde öğrenmeleri gerekmektedir.

\section{Kaynaklar}

1.Sheiham A, Bönecker M. Promoting children's oral health. Theory, practice; 2006;191 pp

2.Jürgensen N, Petersen PE. Oral health and the impact of socio-behavioural factors in a cross sectional survey of 12-year old school children in Laos. BMC Oral Health. 2009 Nov 16;9:29. doi: 10.1186/1472-6831-9-29

3.Akkaya M, Boyraz M, Şevik N, Konak E. Bir Grup Öğrencide Farklı Motivasyon Yöntemlerinin Etkinliklerinin Araştırılması, A.Ü. Diş. Hek. Fak. Derg 1994;21:237-41.

4.Klein H, Palmer CE, Knutson JW. Studies on dental caries. I. Dental status and dental needs of elementary school children. Public Health Rep. 1938;53:751.

5.Astrom A, Jakobsen R. "Stability of Health Dental Behavior". 1996

6.Hamissi J, Ramezani GH, Ghodousi A. Prevalence of dental caries among high school attendees in Qazvin, Iran. J Indian Soc Pedod Prev Dent 2008;26 Suppl 2:S53-5.

7.Ahmed NA, Astrøm AN, Skaug N, Petersen PE. Dental caries prevalence and risk factors among 12- year old schoolchildren from Baghdad, Iraq: a post- war survey. Int Dent $\mathrm{J}$ 2007;57(1):36-44.
8.Al-Sharbati MM, Meidan TM, Sudani O. Oral health practices and dental caries among Libyan pupils, Benghazi (1993-94). East Mediterr Health J 2000;6(5- 6):997-1004.

9.Pontigo-Loyola, Patricia A, Median-Solis, Eduardo C, Borges-Yanez, Aida S. prevalence and severity of dental caries in adolescents aged 12 and 15 living in communities with various fluoride concentrations. Journal of Public Health Dentistry 2007; 67: 8-13.

10.Hassan AH, Amer H, Mossa A, Ghaznawi H. Prevalence and intensity of dental caries among school student in Jeddah city. Egyptian Dent J 2005; 51:1427-32.

11.Al-Darwish M, El Ansari W, Bener A. Prevalence of dental caries among 12-14 year old children in Qatar. Saudi Dent J 2014;26(3):11525.

12.Shailee F, Girish MS, Kapil RS, Nidhi P. Oral health status and treatment needs among 12- and 15-year-old government and private school children in Shimla city, Himachal Pradesh, India. J Int Soc Prev Community Dent 2013;3(1):44-50.

13.Abdullah HA. Prevalence of dental caries and associated teeth brushing behavior among Iraqi adolescents in Al-Door district. Tikrit Medical Journal 2009:15(2):102-9.

14.Levin L, Margvelashvili V, Bilder L, Kalandadze M, Tsintsadze N, Machtei EE. Periodontal status among adolescents in Georgia. A pathfinder study. PeerJ. 2013. Sep 17;1:e137. doi: 10.7717 peerj.137.

15.Al-banyan RA, Echeverrı EA, Narendran S, Keene HJ. Oral health survey of 5-12 year old children of National Guard employees in Riyadh, Saudi Arabia. International Journal of Pediatrics Dentistry 2000:10(1): 39-45.

16.Motlagh GM, A. Kohestani A. An investigation on DMFTand DMFS of first permanent molars in 12-year- old blind children in resi- 
dential institutes for blinds in Tehran (20002001). Journal of Dentistry, Tehran University of Medical Sciences 2004:1(3):56-61.

17. Mehta A, Kaur G. Oral health-related knowledge,

18.attitude, and practices among 12-year-old school- children studying in rural areas of Panchkula, India. Indian J Dent Res 2012 ;23 (2):293.

19.Zhu L, Peterson PE, Wang HY, Bian JY, Zhang BX. Oral health knowledge, attitude and behaviors of adults in China. In Dent J 2005;55 (4):231-41.

20.Varenne B, Petersen PE, Quattara S. Oral health behaviour of children and adults in urban and rural areas of Bukina Faso, Africa. Int Dent J 2006;56(2):61-70

21.El-Qaderi SS, Taani DQ. Oral health knowledge and dental health practices among schoolchildren in Jerah district/Jordan. Int J Dent Hyg 2004;2(2):78-85.

22. Vogel RI, Sullivan AJ, Pascuzzi JN, Deasy NJ. Evaluation of cleansing devices in the maintenance of interproximal gingival health. J Periodontol 1975;46(12):745-7.

23.Saldūnaitė K, Bendoraitienè EA, Slabšinskienė E, Vasiliauskienė I, Andruškevičienè V, Zūbiene $J$. The role of parental education and socioeconomic status in dental caries prevention among Lithuanian children. Medicina (Kaunas) 2014;50(3):156-61.

24.Roldán S, Herrera D, Sanz M. Biofilms and the tongue: therapeutical approaches for the control of halitosis. Clin Oral Investig 2003;7 (4):189-97.
25.Tonzetich J, Ng SK. Reduction of malodor by oral cleansing procedures. Oral Surg Oral Med Oral Pathol 1976;42(2):172-81.

26.Bodur H, Bodur A, Yücesoy V, Baloş K. İki farklı yaş grubunda diş çürüğü prevelansı ve periodontal durumun değerlendirilmesi. GÜ Diş Hek. Derg 2004; 21(1): 35-9.

27.Kida IA, Manyori C, Masalu JR. Prevalence and correlates of perceived oral malodor among adolescents in Temeke district, Dar es Salaam East Afr. J Public Health 2010;7(1):4953.

28.Nalçaci R, Sönmez IS. Evaluation of oral malodor in children. Oral Surg Oral Med Oral Pathol Oral Radiol Endod 2008;106(3):384-8.

29.Calil C, Liberato FL, Pereira AC, de Castro Meneghim M, Goodson JM, Groppo FC. The relationship between volatile sulphur compounds, tongue coating and periodontal disease. Int J Dent Hyg 2009;7(4):251-5.

30.Kharbanda OP, Sidhu SS, Sundaram K, Shukla DK. Oral habits in school going children of Delhi: a prevalence study. J Indian Soc Pedod Prev Dent 2003;21(3):120-4 